\title{
Failed Labor Induction: Toward an Objective Diagnosis
}

\author{
Dwight J. Rouse, M.D., Steven J. Weiner, M.S., Steven L. Bloom, M.D., Michael W. Varner, \\ M.D., Catherine Y. Spong, M.D., Susan M. Ramin, M.D., Steve N. Caritis, M.D., William A. \\ Grobman, M.D., Yoram Sorokin, M.D., Anthony Sciscione, D.O., Marshall W. Carpenter, \\ M.D., Brian M. Mercer, M.D., John M. Thorp Jr., M.D., Fergal D. Malone, M.D., Margaret \\ Harper, M.D., M.S., Jay D. lams, M.D., and Garland D. Anderson, M.D. for the Eunice \\ Kennedy Shriver National Institute of Child Health and Human Development (NICHD) \\ Maternal-Fetal Medicine Units Network (MFMU) ${ }^{\star}$ \\ Department of Obstetrics and Gynecology at the University of Alabama at Birmingham, \\ Birmingham, AL (D.J.R.); University of Texas Southwestern Medical Center, Dallas, TX (S.L.B.); \\ University of Utah, Salt Lake City, UT (M.W.V.); The University of Texas Health Science Center at \\ Houston, Houston, TX (S.M.R.); University of Pittsburgh, Pittsburgh, PA (S.N.C.); Northwestern \\ University, Chicago, IL (W.A.G.); Wayne State University, Detroit, MI (Y.S.); Drexel University, \\ Philadelphia, PA (A.S.); Brown University, Providence, RI (M.W.C.); Case Western Reserve \\ University--MetroHealth Medical Center, Cleveland, $\mathrm{OH}$ (B.M.M.); University of North Carolina at \\ Chapel Hill, Chapel Hill, NC (J.M.T.); Columbia University, New York, NY (F.D.M.); Wake Forest \\ University Health Sciences, Winston-Salem, NC (M.H.); The Ohio State University, Columbus, \\ $\mathrm{OH}$ (J.D.I.); the University of Texas Medical Branch, Galveston, TX (G.D.A.); and The George \\ Washington University Biostatistics Center, Washington, DC (S.J.W.) and the Eunice Kennedy \\ Shriver National Institute of Child Health and Human Development, Bethesda, MD (C.Y.S.)
}

\begin{abstract}
Objective-To evaluate maternal and perinatal outcomes in women undergoing labor induction with an unfavorable cervix according to duration of oxytocin administration in the latent phase of labor after ruptured membranes.
\end{abstract}

\begin{abstract}
Methods-This was a secondary analysis of a randomized multicenter trial in which all cervical examinations from admission were recorded. Inclusion criteria: nulliparas at or beyond 36 weeks of gestation undergoing induction with a cervix of $2 \mathrm{~cm}$ or less dilated and less than completely effaced. The latent phase of labor was defined as ending at a cervical dilation of $4 \mathrm{~cm}$ and effacement of at least $90 \%$, or at a cervical dilation of $5 \mathrm{~cm}$ regardless of effacement.
\end{abstract}

\begin{abstract}
Results-One-thousand three-hundred forty-seven women were analyzed. The overall vaginal delivery rate was $63.2 \%$. Most women had exited the latent phase after 6 hours of oxytocin and membrane rupture; only $5 \%$ remained in the latent phase after 12 hours $(n=940,69.8 \%)$. The longer the latent phase, the lower the vaginal delivery rate. Even so, $39.4 \%$ of the 71 women who remained in the latent phase after 12 hours of oxytocin and membrane rupture were delivered vaginally. Chorioamnionitis, endometritis, or both, and uterine atony were the only maternal adverse outcomes related to latent phase duration: adjusted odds ratios (95\% confidence intervals)
\end{abstract}

(c) Copyright 2011 American College of Obstetricians and Gynecologists.

Corresponding author: Dwight J. Rouse, MD, Brown University, Warren Alpert Medical School, Department of Obstetrics and Gynecology, 101 Dudley Street, 3rd Floor, Providence, RI 02905, drouse@ wihri.org.

*For a list of other members of the NICHD MFMU, see the Appendix online at http://links.lww.com/xxx.

This is a PDF file of an unedited manuscript that has been accepted for publication. As a service to our customers we are providing this early version of the manuscript. The manuscript will undergo copyediting, typesetting, and review of the resulting proof before it is published in its final citable form. Please note that during the production process errors may be discovered which could affect the content, and all legal disclaimers that apply to the journal pertain. 
of $1.12(1.07,1.17)$ and $1.13(1.06,1.19)$, respectively, for each additional hour. Neonatal outcomes were not related to latent phase duration.

Conclusion-Almost $40 \%$ of the women who remained in the latent phase after 12 hours of oxytocin and membrane rupture were delivered vaginally. Therefore, it is reasonable to avoid deeming labor induction a failure in the latent phase until oxytocin has been administered for at least 12 hours after membrane rupture.

\section{Introduction}

In 2006, labor induction was utilized in $22.5 \%$ of United States births. ${ }^{1}$ Despite this high rate, and despite the fact that among nulliparas, labor induction is associated with a doubling of the cesarean rate even after controlling for maternal demographic characteristics, medical risk, and pregnancy complications, ${ }^{2}$ there is no commonly accepted definition of "failed labor induction." Specifically, neither of the two major obstetric textbooks currently in use in the United States, ${ }^{3,4}$ nor the ACOG practice bulletin ${ }^{5}$ on labor induction includes an explicit definition, although the latter acknowledges that "allowing at least 12-18 hours of latent labor before diagnosing a failed induction may reduce the risk of cesarean delivery."

Previously, in a single center prospective study, the utility of a definition of failed labor induction was evaluated. ${ }^{6}$ By protocol, the administration of oxytocin for 12 hours after membrane rupture with no progress into the active phase of labor was required before induction could be deemed to have failed $(n=940,69.8 \%)$. This requirement allowed parturients who remained in the latent phase for up to 12 hours to achieve vaginal deliveries that they otherwise would not have. The utility of this approach was subsequently confirmed in a retrospective study, also single-centered, in which the majority of women with latent phase durations of up to 18 hours were delivered vaginally. ${ }^{7}$ In both of these studies, longer latent phases were not associated with an increased risk of adverse neonatal outcome.

In the present investigation, we took advantage of data collected as part of multi-centered fetal pulse oximetry trial ${ }^{8}$ to evaluate the associated benefits and risks of progressively longer latent phase durations among nulliparas undergoing labor induction at or beyond 36 weeks' gestation.

\section{Material and Methods}

This was a secondary analysis of a clinical trial of fetal pulse oximetry conducted at the 14 clinical centers of the Eunice Kennedy Shriver National Institute of Child Health and Human Development Maternal-Fetal Medicine Units Network. ${ }^{8}$ Participants in that trial were nulliparas carrying a singleton vertex fetus who were undergoing labor induction or laboring spontaneously at or beyond 36 weeks' gestation. To be eligible for randomization and oximeter placement, the cervix had to be at least $2 \mathrm{~cm}$ dilated and the fetal vertex at or below -2 station. The present analysis was confined to participants who underwent oxytocin labor induction with an unfavorable cervix, defined as no more than $2 \mathrm{~cm}$ dilated and less than completely effaced, who ultimately met the dilation and station requirements of the clinical trial. Women were included regardless of their membrane status at the initiation of induction. Ruptured membranes were required for placement of the fetal pulse oximeter. However, timing of artificial rupture of membranes was not codified by the study protocol, but instead was left to the discretion of the managing clinicians. Exclusion criteria for the trial included maternal fever immediately prior to randomization, infections such as active genital herpes, HIV, hepatitis B or C, and chronic conditions such as diabetes mellitus, heart disease treated with medication, and renal disease. Pregnancy-associated hypertension was not an exclusion criterion. Each participating center had Institutional Review Board approval for the study. 
Maternal and neonatal data were collected by trained research nurses who were present throughout labor to adjust the fetal oximeter. They recorded the results of all cervical examinations, including the time at which they were obtained, into the study database. Cervical examinations were performed by managing clinicians, not the research nurses. For this study, the diagnosis of chorioamnionitis required that the clinical diagnosis had been made, the intrapartum temperature reached at least $38^{\circ} \mathrm{C}$, and at least one of the following was present: uterine tenderness, foul smelling vaginal discharge or amniotic fluid, or maternal or fetal tachycardia. The study diagnosis of endometritis required a clinical diagnosis and a post-partum temperature of at least $38^{\circ} \mathrm{C}$. Other maternal morbidities were defined on the basis of clinical diagnoses. Perineal laceration data were collected only for women who delivered vaginally.

Neonatal morbidities were defined on the basis of clinical diagnoses. In the original trial, ${ }^{8}$ a composite outcome of serious neonatal morbidity was defined a priori, and consisted of any of the following: a 5-minute Apgar score below 4, an umbilical artery $\mathrm{pH}$ value under 7.0, seizures, intubation in the delivery room, stillbirth, neonatal death, or admission to a neonatal intensive care unit (NICU) for more than 48 hours. Infants who experienced more than one component of the composite were represented only once in the composite outcome analysis.

A woman was considered to be in the latent phase of labor until her cervical dilation had progressed to $4 \mathrm{~cm}$ and at least $90 \%$ effaced, or to $5 \mathrm{~cm}$ regardless of effacement. ${ }^{6}$ Maternal and neonatal outcomes were assessed based on the duration of membrane rupture and concomitant oxytocin receipt in the latent phase of labor. Frequencies are displayed with three-hour latent phase epochs: $<3 \mathrm{hrs}, 3-<6 \mathrm{hrs}, 6-<9 \mathrm{hrs}$, etc.; however all statistical tests, other than those involving baseline and demographic comparisons, employed a continuous measure of latent phase duration. Baseline and demographic comparisons between those with latent phase less than 6 hours compared with 6 hours or more utilized the Wilcoxon rank-sum test (continuous variables), and the chi-square or Fisher's exact test (continuous variables). Associations between duration of the latent phase and the various dichotomous maternal and neonatal outcomes were analyzed using standard logistic regression, with adjustment for maternal race and ethnicity, gestational age at delivery, body mass index at delivery $\left(\mathrm{kg} / \mathrm{m}^{2}\right.$ ), and study treatment arm (main effects only). All reported $\mathrm{P}$ values are two-sided and a $\mathrm{P}<0.05$ was considered significant. No adjustments were made for multiple comparisons. SAS software (SAS Institute, Inc, Cary, NC) was used for analysis.

\section{Results}

Of 5,341 parturients enrolled in the clinical trial from May 2002 to February 2005, 1,347 (25.2\%) underwent labor induction with a cervix that was no more than $2 \mathrm{~cm}$ dilated and that was less than completely effaced. These 1,347 women and their neonates constitute the study cohort (Table 1).

The 1220 women who began induction with intact membranes received oxytocin for a median (range) of $2.8(0.0,49.8)$ hours prior to membrane rupture and their induction to delivery interval was $16.5(3.8,123.1)$ hours. In $310(25.4 \%)$ of these 1220 women, cervical ripening was initiated with a prostaglandin $9.0(0.1,103.7)$ hours prior to oxytocin initiation, in $274(22.5 \%)$ ripening was initiated with a Foley balloon catheter $0.5(0.0,30.3)$ hours prior to oxytocin initiation, and in $33(2.7 \%)$ ripening was initiated with a prostaglandin and Foley balloon catheter $12.7(3.2,82.6)$ hours prior to oxytocin initiation. The 122 women who began induction with ruptured membranes had a median induction to delivery interval of $15.5(4.2,38.3)$ hours. 
Within six hours after receiving oxytocin with ruptured membranes, most women had entered the active phase of labor. Women who had not were more likely to be Black or Hispanic and of higher body mass index, and to have begun induction with a more unfavorable cervix (all $\mathrm{p}<0.01)$ (Table 1$)$.

The rate of cesarean delivery rose significantly as duration of oxytocin use with ruptured membranes in the latent phase increased ( $\mathrm{p}<0.001$, logistic regression). Even so, 39.4\% ( $95 \% \mathrm{CI}, 28.1 \%$ to $50.8 \%$ ) of women who remained in the latent phase after 12 hours of oxytocin with ruptured membranes were delivered vaginally (Table 2). Rates of chorioamnionitis and endometritis were positively associated with latent phase duration, as was uterine atony (Tables 3 and 4). There were no intrapartum or neonatal deaths, and no cases of hypoxic ischemic encephalopathy. Neonatal morbidities were not associated with duration of latent phase (Tables 3 and 4). Four infants were diagnosed with bacterial sepsis in the neonatal period. The durations of the latent phase in these cases ranged from 57 minutes to 7 hours, 5 minutes.

Overall, 57 women, or $4.2 \%$ (95\% CI, 3.2\% to $5.3 \%$ ), underwent cesarean delivery while still in the latent phase. Of these, 42 (73.7\%) were delivered for "dystocia" and 15 (26.3\%) for non-reassuring fetal status.

Not surprisingly, initial cervical dilation was correlated with the likelihood of both reaching the active phase, and of delivering vaginally. Of the 1,347 women in our cohort, 774 $(57.5 \%)$ began induction with a cervix that was no more dilated than one centimeter, and $573(42.5 \%)$ began induction at two centimeters dilation. Women in the former group were slightly less likely to reach the active phase $(94.6 \%$ vs. $97.4 \%, \mathrm{p}=0.01)$ and also less likely to deliver vaginally $(58.8 \%$ vs. $69.1 \%, \mathrm{p}<0.001)$.

\section{Discussion}

In our cohort of nulliparas who underwent labor induction, we found that almost $40 \%$ of women who remained in the latent phase after 12 hours of oxytocin with ruptured membranes were delivered vaginally. These data, prospectively collected from 14 centers, broaden our understanding of the benefits and risks of progressively longer latent phase durations among nulliparas undergoing labor induction. They are consistent with two prior single center investigations that showed progressively lower rates of vaginal delivery with longer durations of the latent phase, and higher rates of associated maternal infection, but no increase in neonatal morbidity rates. ${ }^{6,7}$ All three studies report outcomes with the same reproducible metric (duration of oxytocin administration after membrane rupture) and utilize a common definition of the latent phase, defined in terms of cervical dilation and effacement.

The first of the single center studies, by Rouse et al., included 361 nulliparas who underwent labor induction with an unfavorable cervix at or beyond 36 weeks' gestation. ${ }^{6}$ Their overall cesarean delivery rate was $25 \%$. In their study cohort, 13 of the 15 women $(87 \%)$ who had not entered the active phase (cervical dilation of $\geq 4 \mathrm{~cm}$ and effacement $\geq 90 \%$ or cervical dilation $25 \mathrm{~cm}$ regardless of effacement) by 12 hours ultimately were delivered by cesarean, and $27 \%$ were diagnosed with chorioamnionitis. No other maternal or neonatal morbidities were correlated with the duration of the latent phase.

In the second single center study, by Simon and Grobman, 397 nulliparas who underwent labor induction at 36 weeks' gestation or greater were evaluated. ${ }^{7}$ The overall cesarean delivery rate for these women was $26 \%$. Only 19 women (5\%) had latent phase durations that exceeded 18 hours, and their cesarean delivery rate was $68 \%$. However, 2/3 of the women with latent phase durations of 15-18 hours were delivered vaginally, and vaginal 
delivery rates were even higher for women with shorter latent phase durations. In addition to chorioamnionitis, post-partum hemorrhage was correlated with latent phase duration, but blood transfusion or other maternal or neonatal morbidities were not.

In the present investigation of 1,347 nulliparas, cesarean delivery rates vis-à-vis latent phase durations were intermediate between the two above studies. For example, in this study, women with latent phase durations of at least 12 hours had a $61 \%$ cesarean delivery rate, as compared to $87 \%$ in the Rouse study and $41 \%$ in the Simon and Grobman study. Maternal infection rates were comparable, and, similar to the increased rate of post-partum hemorrhage in the Simon and Grobman study, the rate of uterine atony, but not blood transfusion, was increased in the present investigation as the duration of the latent phase increased. In all three studies, failure to exit the latent phase after 12 hours of oxytocin and ruptured membranes was uncommon: $4 \%,{ }^{6} 17 \%,{ }^{7}$ and $5 \%$ (present study).

In a similar study, Blackwell et al. reported that the $50^{\text {th }}$ percentile of latent phase duration for nulliparas who underwent labor induction and delivered vaginally was 11 hours, and the $90^{\text {th }}$ percentile was 27 hours. In their study, latent phase duration was calculated as the time from the initiation of cervical ripening until $4 \mathrm{~cm}$ of cervical dilation, and this duration was not correlated with adverse outcomes, either maternal or perinatal. ${ }^{9}$

The strengths of our data are that they were prospectively accrued, reflect practice patterns and outcomes from 14 centers, and were collected by trained and certified research nurses present during labor.

Weaknesses of our data include the fact that labor management was not standardized which limits the value of the causal implications of the data. That is, the complications that we observed in association with latent phase duration may not per se be due to duration, or at least duration alone. Similarly, for several of the complications, our study design does not allow us to say that the complications would have been avoided if the latent phase had been shorter. Another potential weakness is that even with a sample size of over 1,300 women, our statistical power to detect an increased risk of infrequent complications in association with the duration of the latent phase was low, especially for those who remained in the latent phase beyond 12 hours. This same limitation applies to all previous studies. ${ }^{6,7,9}$

A further limitation of our data is that only women who achieved cervical dilations of at least $2 \mathrm{~cm}$ and fetal stations at or below -2 were included in this secondary analysis (otherwise they would not have been eligible for the parent clinical trial). Thus our data are not representative of women who undergo induction and do not achieve these thresholds. Such women, however, are clearly in the minority. In the study of Rouse et al., only $8 \%$ of nulliparas did not progress to the active phase, ${ }^{6}$ and in the study of Simon and Grobman, only $2 \%$ did not. ${ }^{7}$ Since $98 \%$ of women in the study cohort received epidural analgesia, our findings may not be generalizable to women who labor without such analgesia. Finally, since we studied only nulliparous women, our data do not speak to management of multiparous women.

In conclusion, our data support that the reproducible metrics of duration of oxytocin administration after membrane rupture, and time in the latent phase may be useful in moving toward a definition of failed labor induction. Any such definition will involve judgments and tradeoffs. But pending further study, an argument can be made on the basis of the available data that requiring at least twelve hours of oxytocin after ruptured membranes before declaring an induction to have failed in the latent phase reasonably balances maternal benefits, i.e., the opportunity for vaginal delivery, with maternal risks, specifically chorioamnionitis and uterine atony. Reassuringly, with contemporary management, any 
fetal/neonatal risks associated with labor induction do not seem to be affected by latent phase duration.

\section{Acknowledgments}

The authors thank Kenneth J. Leveno, M.D. for protocol development and oversight, Elizabeth Thom, Ph.D., for protocol and data management and statistical analysis, Allison T. Northen, M.S.N., R.N. forprotocol development and coordination between clinical research centers, and Donald McIntire, Ph.D., for study design.

Supported by grants from the Eunice Kennedy Shriver National Institute of Child Health and Human Development (NICHD) [HD21410, HD27860, HD27869, HD27915, HD27917, HD34116, HD34136, HD34208, HD40485, HD40500, HD40512, HD40544, HD40545, HD40560, and HD36801] and does not necessarily represent the official views of the NICHD or the NIH.

\section{Appendix}

In addition to the authors, other members of the Eunice Kennedy Shriver National Institute of Child Health and Human Development Maternal-Fetal Medicine Units Network are as follows:

University of Alabama at Birmingham - A. Northen, K. Bailey, J. Grant, S. Tate, and T. Hill-Webb

Brown University — J. Tillinghast, D. Allard, P. Breault, N. Connolly, and J. Silva

Case Western Reserve University--MetroHealth Medical Center - C. Milluzzi, C. Heggie, H. Ehrenberg, and B. Stetzer

Columbia University - V. Pemberton, S. Bousleiman, H. Husami, V. Carmona, and S. South

Drexel University - M. Talucci, M. Pollock, M. Sherman, C. Tocci, and E. Seltzer

University of North Carolina at Chapel Hill - S. Brody, J. Granados, K. Clark, J. Mitchell, and K. Dorman

Northwestern University - G. Mallett, N. Cengic, M. Huntley, and T. Triplett

The Ohio State University - F. Johnson, S. Fyffe, and M. Landon

University of Pittsburgh - M. Cotroneo, M. Luce, H. Birkland, M. Bickus, and L. Creswell-Hartman

The University of Texas Health Science Center at Houston - M.C. Day, F. Ortiz, B. Figueroa, S. Shaunfield, and M. Messer

University of Texas Southwestern Medical Center - J. McCampbell and L. Moseley

University of Utah - K. Anderson, B. Oshiro (McKay-Dee Hospital), F. Porter (Intermountain Healthcare), K. Jolley (Utah Valley Regional Medical Center), and A. Guzman (McKay-Dee Hospital)

Wake Forest University Health Sciences - M. Swain, J. Chilton, C. Leftwich, W. Davido, and K. Johnson

Wayne State University — G. Norman, B. Steffy, C. Sudz, and S. Blackwell 
The George Washington University Biostatistics Center - E.A. Thom, A. Swanson, F. Galbis-Reig, and L. Leuchtenburg

Eunice Kennedy Shriver National Institute of Child Health and Human Development - S. Tolivaisa and K. Howell

\section{References}

1. Martin, JA.; Hamilton, BE.; Sutton, PD.; Ventura, SJ., et al. Births: Final data for 2006. National vital statistics reports. Vol. 57. National Center for Health Statistics; Hyattsville, MD: 2009.

2. Ehrenthal DB, Jiang X, Strobino DM. Labor induction and risk of a cesarean delivery among nulliparous women at term. Obstet Gynecol. 2010; 116:35-42. [PubMed: 20567165]

3. Cunningham, FG.; Leveno, KJ.; Bloom, SL.; Hauth, JC.; Rouse, DJ.; Spong, CY. Williams Obstetrics. 23rd edition. McGraw Hill; New York (NY): 2009.

4. Gabbe, SG.; Neibyl, JR.; Simpson, JL. Obstetrics: Normal and Problem Pregnancies. 5th edition. Churchill Livinstone Elsevier; Philidelphia (PA): 2007.

5. American College of Obstetricians and Gynecologists. ACOG Practice Bulletin No. 107 Induction of Labor. 2009

6. Rouse DJ, Owen J, Hauth J. Criteria for failed labor induction: Prospective evaluation of a standardized protocol. Obstet Gynecol. 2000; 96:671-7. [PubMed: 11042299]

7. Simon CE, Grobman WA. When has an induction failed? Obstet Gynecol. 2005; 105:705-9. [PubMed: 15802394]

8. Bloom SL, Spong CY, Thom E, Varner MW, Rouse DJ, Weininger S, et al. Fetal pulse oximetry and cesarean delivery. N Engl J Med. 2006; 355:2195-202. [PubMed: 17124017]

9. Blackwell SC, Refuerzo J, Chadha R, Samson J. Duration of labor induction in nulliparous women at term: How long is long enough? Am J Perinatol. 2008; 25:205-209. [PubMed: 18548392] 
Table 1

Maternal Demographic and Intrapartum Characteristics

\begin{tabular}{|c|c|c|}
\hline & \multicolumn{2}{|c|}{ Length of latent phase } \\
\hline & $\begin{array}{l}\text { Less than } 6 \text { hours } \\
(\mathrm{n}=940)\end{array}$ & $\begin{array}{l}6 \text { hours or more } \\
(n=407)\end{array}$ \\
\hline Age (y) & $23.9 \pm 5.4$ & $23.9 \pm 5.6$ \\
\hline \multicolumn{3}{|l|}{ Race } \\
\hline Black & $280(29.8)$ & $140(34.4)$ \\
\hline White & $591(62.9)$ & $207(50.9)$ \\
\hline Asian & $9(1.0)$ & $5(1.2)$ \\
\hline Other & $60(6.4)$ & $55(13.5)$ \\
\hline \multicolumn{3}{|l|}{ Body mass index $\left(\mathrm{kg} / \mathrm{m}^{2}\right)$} \\
\hline Pre-pregnancy & $25.8 \pm 6.2$ & $27.6 \pm 7.1$ \\
\hline Delivery & $31.9 \pm 6.3$ & $33.7 \pm 7.0$ \\
\hline \multicolumn{3}{|l|}{ Ethnic group } \\
\hline Hispanic or Latino & $135(14.4)$ & $85(20.9)$ \\
\hline Not Hispanic or Latino & $805(85.6)$ & $322(79.1)$ \\
\hline Gestational age (wk) & $39.9 \pm 1.4$ & $39.9 \pm 1.5$ \\
\hline \multicolumn{3}{|l|}{ Indication for labor induction } \\
\hline Post-term & $289(30.7)$ & $112(27.5)$ \\
\hline Gestational hypertension & $197(21.0)$ & $74(18.2)$ \\
\hline Oligohydramnios & $85(9.0)$ & $45(11.1)$ \\
\hline Premature rupture of membranes & $31(3.3)$ & $54(13.3)$ \\
\hline Other maternal or fetal indication & $154(16.4)$ & $82(20.1)$ \\
\hline Elective & $184(19.6)$ & $40(9.8)$ \\
\hline \multicolumn{3}{|l|}{ Cervical ripening agents } \\
\hline Prostaglandin & $217(23.1)$ & $105(25.8)$ \\
\hline Foley Catheter & $202(21.5)$ & 77 (18.9) \\
\hline Both & $24(2.6)$ & $11(2.7)$ \\
\hline None & $497(52.9)$ & $214(52.6)$ \\
\hline Use of epidural analgesia & $917(97.6)$ & $401(98.5)$ \\
\hline \multicolumn{3}{|l|}{ Type of delivery } \\
\hline Spontaneous & $489(52.0)$ & $168(41.3)$ \\
\hline Operative vaginal & $155(16.5)$ & $39(9.6)$ \\
\hline Cesarean & $296(31.5)$ & $200(49.1)$ \\
\hline \multicolumn{3}{|l|}{ Initial Cervical Dilation $(\mathrm{cm})$} \\
\hline 0 & $120(12.8)$ & $73(17.9)$ \\
\hline
\end{tabular}




\begin{tabular}{|l|l|l|}
\hline & \multicolumn{2}{l|}{ Length of latent phase } \\
\hline & $\begin{array}{l}\text { Less than 6 hours } \\
\text { (n= 940) }\end{array}$ & $\begin{array}{l}\text { 6 hours or more } \\
\text { (n= 407) }\end{array}$ \\
\hline 1 & $433(46.1)$ & $249(61.2)$ \\
2 & $387(41.2)$ & $85(20.9)$ \\
\hline Initial Cervical Effacement (\%) & \multicolumn{2}{|c}{} \\
$0-25 \%$ & $184(19.6)$ & $129(31.7)$ \\
$30-50 \%$ & $279(29.7)$ & $155(38.1)$ \\
$60-75 \%$ & $223(23.7)$ & $73(17.9)$ \\
$80-90 \%$ & $232(24.7)$ & $41(10.1)$ \\
Unknown & $22(2.3)$ & $9(2.2)$ \\
\hline
\end{tabular}

Data are presented as mean \pm standard deviation, or number (percent) 
Table 2

Length of Latent Phase and Delivery Mode

\begin{tabular}{|c|c|c|c|c|}
\hline & & & \multicolumn{2}{|c|}{ Eventual delivery route } \\
\hline $\begin{array}{l}\text { Time since start } \\
\text { of oxytocin with } \\
\text { ruptured } \\
\text { membranes }\end{array}$ & $\begin{array}{l}\text { Labor status at end of } \\
\text { interval (for those who } \\
\text { started interval in the } \\
\text { latent phase) }\end{array}$ & & Vaginal & Cesarean \\
\hline \multirow[t]{4}{*}{$0-<3 \mathrm{hrs}$} & Achieved active phase & $425 / 1347$ (31.6) & $304 / 425(71.5)$ & $121 / 425(28.5)$ \\
\hline & Remain in latent phase & $918 / 1347(68.2)$ & $547 / 918(59.6)$ & $371 / 918(40.4)$ \\
\hline & $\begin{array}{l}\text { Were delivered in } \\
\text { latent phase }\end{array}$ & 4/1347 (0.3) & $0 / 4(0.0)$ & $4 / 4(100)$ \\
\hline & Overall & & $851 / 1347(63.2)$ & $496 / 1347(36.8)$ \\
\hline \multirow[t]{4}{*}{$3-<6 \mathrm{hrs}$} & Achieved active phase & $507 / 918(55.2)$ & $340 / 507(67.1)$ & $167 / 507(32.9)$ \\
\hline & Remain in latent phase & 407/918 (44.3) & 207/407 (50.9) & 200/407 (49.1) \\
\hline & $\begin{array}{l}\text { Were delivered in } \\
\text { latent phase }\end{array}$ & 4/918 (0.4) & $0 / 4(0.0)$ & 4/4 (100) \\
\hline & Overall & & $547 / 918(59.6)$ & $371 / 918(40.4)$ \\
\hline \multirow[t]{4}{*}{$6-<9 \mathrm{hrs}$} & Achieved active phase & 235/407 (57.7) & $143 / 235(60.9)$ & $92 / 235(39.1)$ \\
\hline & Remain in latent phase & $161 / 407$ (39.6) & 64/161 (39.8) & $97 / 161(60.2)$ \\
\hline & $\begin{array}{l}\text { Were delivered in } \\
\text { latent phase }\end{array}$ & $11 / 407(2.7)$ & $0 / 11(0.0)$ & $11 / 11(100)$ \\
\hline & Overall & & 207/407 (50.9) & 200/407 (49.1) \\
\hline \multirow[t]{4}{*}{$9-<12 \mathrm{hrs}$} & Achieved active phase & 75/161 (46.6) & $36 / 75(48.0)$ & $39 / 75(52.0)$ \\
\hline & Remain in latent phase & $71 / 161(44.1)$ & 28/71 (39.4) & 43/71 (60.6) \\
\hline & $\begin{array}{l}\text { Were delivered in } \\
\text { latent phase }\end{array}$ & $15 / 161(9.3)$ & $0 / 15(0.0)$ & $15 / 15(100)$ \\
\hline & Overall & & $64 / 161(39.8)$ & $97 / 161(60.2)$ \\
\hline \multirow[t]{3}{*}{12 or more hrs } & Achieved active phase & $48 / 71(67.6)$ & $28 / 48(58.3)$ & 20/48 (41.7) \\
\hline & $\begin{array}{l}\text { Were delivered in } \\
\text { latent phase }\end{array}$ & 23/71 (32.4) & $0 / 23(0.0)$ & $23 / 23(100)$ \\
\hline & Overall & & 28/71 (39.4) & $43 / 71(60.6)$ \\
\hline
\end{tabular}

Data are presented as proportions (percent) 
Table 3

Length of Latent Phase and Morbidities

\begin{tabular}{|l|l|l|l|l|l|l|l|}
\hline $\begin{array}{l}\text { Time since } \\
\text { start of } \\
\text { oxytocin } \\
\text { with } \\
\text { ruptured } \\
\text { membranes }\end{array}$ & $\begin{array}{l}\text { Number } \\
\text { of } \\
\text { women } \\
\text { in latent } \\
\text { phase at } \\
\text { start of } \\
\text { interval }\end{array}$ & $\begin{array}{l}\text { Chorio- } \\
\text { amnionitis } \\
\text { /Endometritis }\end{array}$ & $\begin{array}{l}\mathbf{3}^{\text {rd }} \text { or } \text { 4 }^{\text {degree }} \\
\text { perineal } \\
\text { laceration } \\
*\end{array}$ & $\begin{array}{l}\text { Uterine } \\
\text { atony }\end{array}$ & $\begin{array}{l}\text { NICU } \\
\text { admission }\end{array}$ & $\begin{array}{l}\text { NICU } \\
\text { admission } \\
\text { hours }\end{array}$ & $\begin{array}{l}\text { Neonatal } \\
\text { composite } \\
\#\end{array}$ \\
\hline $0-<3 \mathrm{hrs}$ & 1347 & $178(13.2)$ & $78(9.2)$ & $63(4.7)$ & $83(6.2)$ & $44(3.3)$ & $57(4.2)$ \\
\hline $3-<6 \mathrm{hrs}$ & 918 & $146(15.9)$ & $55(10.1)$ & $52(5.7)$ & $55(6.0)$ & $31(3.4)$ & $40(4.4)$ \\
\hline $6-<9 \mathrm{hrs}$ & 407 & $93(22.9)$ & $24(11.6)$ & $35(8.6)$ & $30(7.4)$ & $15(3.7)$ & $21(5.2)$ \\
\hline $9-<12 \mathrm{hrs}$ & 161 & $45(28.0)$ & $6(9.4)$ & $16(9.9)$ & $14(8.7)$ & $7(4.3)$ & $10(6.2)$ \\
\hline $\begin{array}{l}12 \text { or more } \\
\text { hrs }\end{array}$ & 71 & $22(31.0)$ & $3(10.7)$ & $8(11.3)$ & $7(9.9)$ & $2(2.8)$ & $4(5.6)$ \\
\hline
\end{tabular}

Data are presented as number (percent)

* Vaginal deliveries only

${ }^{\#}$ Any of the following: a 5-minute Apgar score below 4, an umbilical artery pH under 7.0, seizures, intubation in the delivery room, stillbirth, neonatal death, or admission to a neonatal intensive care unit for more than 48 hours 
Table 4

Odds Ratios for Each Hour of the Latent Phase*

\begin{tabular}{|l|l|l|l|l|}
\hline Outcome & $\begin{array}{l}\text { Crude OR } \\
\text { (95\% CI) }\end{array}$ & p-value & $\begin{array}{l}\text { Adjusted } \\
\mathbf{( 9 5 \%} \text { CI })\end{array}$ & p-value \\
\hline $\begin{array}{l}\text { Vaginal delivery } \\
\text { Chorioamnionitis/ }\end{array}$ & $0.94(0.91,0.97)$ & $<0.001$ & $0.94(0.91,0.98)$ & 0.001 \\
$\begin{array}{l}\text { Endometritis } \\
\text { Uterine atony }\end{array}$ & $1.13(1.09,1.18)$ & $<0.001$ & $1.12(1.07,1.17)$ & $<0.001$ \\
NICU admission & $1.03(0.96,1.09)$ & 0.43 & $1.03(0.96,1.09)$ & 0.46 \\
$\begin{array}{l}\text { NICU admission } \\
>48 \text { hours }\end{array}$ & $1.00(0.92,1.10)$ & 0.94 & $1.01(0.92,1.10)$ & 0.90 \\
Neonatal & $1.00(0.93,1.09)$ & 0.95 & $1.01(0.93,1.10)$ & 0.81 \\
\hline
\end{tabular}

$\mathrm{OR}=$ odds ratio, $\mathrm{CI}=$ confidence interval

*

1,290 women who achieved the active phase of labor

** Odds ratios adjusted for maternal race/ethnicity, gestational age at delivery, body mass index at delivery, and study treatment arm

\# Any of the following: a 5-minute Apgar score below 4, an umbilical artery pH under 7.0, seizures, intubation in the delivery room, stillbirth, neonatal death, or admission to a neonatal intensive care unit for more than 48 hours 